\title{
O PARASITA DA FAMÍLIA: SOBRE A METAMORFOSE DE KAFKA ${ }^{489}$
}

\author{
MODESTO CARONE
}

A metamorfose foi escrita no outono de 1912, quando Kafka tinha 29 anos de idade, mas só foi publicada em novembro de 1915. Foi uma das poucas coisas que ele publicou em vida e talvez isso tenha contribuído para que a estranha história do homem metamorfoseado em inseto se transformasse numa das principais marcas registradas da ficção kafkiana. Mas o seu extraordinário poder de atração - e de repulsão - não se limita a este acidente de ordem biobibliográfica. Esse fascínio se deve antes ao efeito de choque que desde a primeira frase a novela provoca na mente do leitor. Pois já nas primeiras linhas do texto se manifesta a colisão entre a linguagem tipicamente cartorial, de protocolo, e o pressuposto inverossímil da coisa narrada. O espanto do leitor, aliás, é confirmado pelo número crescente de análises e interpretações de $A$ metamorfose: basta referir que uma bibliografia não muito recente sobre Kafka registra nada menos que 128 títulos dedicados exclusivamente á exegese desta novela. As análises vão desde as de natureza teológica e sociológica até as históricas e estilísticas, passando pelas filosóficas (principalmente existencialistas) e por outras que se podem considerar psicanalíticas de destinação biográfica.

Seria impossível, aqui, dar uma visão (mesmo panorâmica) desses trabalhos, todos eles seguramente empenhados na coerência interna dos seus termos e no esforço para extrair da obra o maior volume possível de significado. Mas de uma maneira geral essas interpretações esbarram na dificuldade material de explicar a circunstância embaraçosa - e no entanto decisiva - da transformação do herói em inseto. Isso porque a metamorfose de Gregor Samsa, que é o acontecimento determinante da história, não admite, do modo peculiar como ela se impõe à leitura, ser captada linearmente, seja como uma alegoria acessível a todos, seja como uma alegoria particular de Kafka, seja como um símbolo veiculado pela tradição. Sendo assim, resta ao leitor o desconforto de deparar com uma narração translúcida, mas cujo ponto de partida permanece opaco. Noutras palavras a novela deslancha a partir de um dado fundamental para a economia do texto sem que o seu sentido seja claramente formulado pelo autor. Acresce que as causas da metamorfose em inseto são um enigma não só para quem lê, como também para o próprio herói. Tanto é assim que, já no segundo parágrafo, depois de ter feito uma inspeção na parte visível do seu corpo - onde sobressaem as saliências do ventre marrom e a fragilidade das inúmeras perninhas que se mexem - Gregor Samsa pergunta: "O que aconteceu comigo?". E o narrador acrescenta, de uma forma suficientemente categórica para não alimentar falsas esperanças em ninguém: "Não era um sonho".

Dito de outro modo, a metamorfose em inseto é postulada pela novela como algo definitivo: ela não é um pesadelo do qual se pudesse acordar. Pelo contrário, no registro costumeiro das inversões kafkianas, é o próprio metamorfoseado quem desperta para este pesadelo. Portanto, a metamorfose não está aí como um disparate, mas como uma licença poética transformada em fato - com o qual, aliás, tanto o herói como o leitor têm que se conformar. Nesse sentido, o narrador não procura nem esclarecer, nem ironizar a metamorfose, limitando-se (digamos assim) a constatá-la com a maior cara-de-pau. Para ele, ela tem o caráter impositivo de um sucesso natural contra o qual não há como protestar. Mesmo a comparação com uma catástrofe natural só tem valor relativo, porque esta de

\footnotetext{
489 "O parasita da família”, conferência pronunciada na Sociedade Brasileira de Psicanálise de São Paulo em 1983, por ocasião do centenário de nascimento de Franz Kafka; in Ruth Röhl (org.) A expressão da modernidade no século XX, São Paulo, FFLCH-USP, 1996, p. 21-30.
} 
alguma maneira se encaixa num contexto inteligível do mundo. Isto é: mesmo quando a catástrofe natural ocorre de um modo irregular, não previsto, pode-se indagar sem constrangimentos pelas suas origens. A metamorfose de um único homem num inseto monstruoso é, nessa direção, algo incomparável, é um caso singular - ainda que se conceda que uma transfiguração similar pudesse acontecer a outra pessoa. Por sinal que essa possibilidade é aventada pelo próprio Gregor em relação ao gerente da firma que o vem buscar em casa. "Gregor procurou imaginar se não poderia acontecer ao gerente algo semelhante ao que hoje se passara com ele: sem dúvida era preciso admitir essa possibilidade".

Pondo de lado a malícia narrativa que neste trecho procura neutralizar, com uma naturalidade sinistra, a metamorfose antinatural da figura central em inseto, o fato é que a novela não pretende torná-la nem imediatamente acessível ao entendimento, nem muito menos universal. Ao contrário, é visível que o narrador se esforça o tempo todo - e com uma agilidade admirável - para que o leitor acabe se esquecendo até do caráter ilusionista da própria ficção, compensando o abalo inicial da história com a notação minuciosa e quase naturalista dos seus desdobramentos.

É evidente, entretanto, que o tema da metamorfose não é novo em literatura: os mitos clássicos e as fábulas, as narrativas dos povos primitivos e os contos de fadas são ricos em acontecimentos como este. Mas nenhum leitor esclarecido fica perturbado com eles, não só porque essas metamorfoses em geral são reversíveis, mas também porque podem ser logo percebidas como manifestações de um estágio de consciência ingênuo, pré-científico, que exime o leitor de julgá-los segundo os padrões de sua própria experiência. Assim é que nós aceitamos que Circe, na Odisséia, metamorfoseie os companheiros de Ulisses em porcos, ou que, num conto de Grimm, o filho do rei vire sapo até que uma princesa o devolva à sua condição natural - justamente porque nestes casos vigora o princípio da diferença entre o mundo empírico conhecido e o mundo mágico, fantástico ou irônico da poesia - o que nos coloca na postura certa enquanto leitores. É esse princípio que falta em A metamorfose, e talvez seja por isso que dela se desprenda uma sensação extraordinariamente perturbadora e penosa que nos põe numa atitude de defesa.

É claro que para esta impressão penosa contribui também um recurso técnico eficaz que é o foco narrativo escolhido por Kafka. Sua peculiaridade consiste no fato de que não é o inseto-personagem quem conta a história, não obstante ela seja narrada da perspectiva do herói. Essa manobra é possível, aqui, graças à existência de um narrador desprovido de qualquer marca pessoal que o autorizasse, por exemplo, a fazer reflexões ou comentários esclarecedores sobre a história que está relatando. Em outros termos, esse narrador se comporta como uma câmera cinematográfica na cabeça do protagonista - e nesse caso o relato objetivo por meio do discurso direto e indireto se entrelaça com a proximidade daquilo que é experimentado subjetivamente pelo herói. É por esse motivo que, na descrição dos acontecimentos que evoluem no seio da família Samsa, a narração não avança muito mais do que Gregor poderia fazer a partir de um ponto de vista rigorosamente pessoal. Na verdade, só no final, quando Gregor está morto e se focalizam os movimentos da família, é que essa perspectiva muda de lugar - e aqui se coloca o problema de uma possível quebra de unidade no modo de narrar privilegiado por Kafka.

Eu vou me deter um instante nessa questão do narrador kafkiano. Na realidade, o narrador inventado por Kafka tem muito pouco a ver com o narrador do romance ou da novela tradicional, que como sabemos se caracteriza sobretudo pela onisciência. Isso quer dizer que o narrador tradicional, pré-kafkiano, não só tem acesso imediato à intimidade mais profunda dos seus personagens, como também dispõe de uma visão panorâmica do conjunto da história que está narrando - embora ele se comporte como se estivesse contando essa história sem ter conhecimento prévio dos seus desdobramentos ou do seu desfecho. Assim no Dom Quixote, o narrador sabe, a respeito do seu herói, muito mais coisas do que este sabe a seu próprio 
respeito. É nesse sentido que Quixote, o personagem, ignora que está confundindo a fantasia com a realidade, e por isso toma moinhos de vento por gigantes que segundo ele é preciso combater pelas regras da Cavalaria Andante; ao passo que o narrador de Cervantes circunscreve rigorosamente as maluquices do herói, tornando-as compreensíveis, cômicas e tranquiilizadoras, através de comentários que estabelecem a necessária distância estética entre a consciência perturbada do protagonista e a armação geral daquilo que está sendo narrado. Numa avaliação histórica muito sumária dessa circunstância estética, é possível identificar, no narrador onisciente um estado do mundo em que a situação do indivíduo estava garantida pela possibilidade de torná-la inteligível numa totalidade social transparente. Pois em Kafka a única coisa transparente que ainda resta é a linguagem - que por sinal é uma linguagem ironicamente conservadora. Mas mesmo a linguagem transparente de Kafka só dá acesso a um contexto de visões parceladas, a um universo fraturado e sem certezas, ou seja: a um mundo tornado opaco e impenetrável - onde, por conseqüência, a manutenção de um narrador que soubesse de tudo soaria como uma falsificação dos seus próprios pressupostos. Nesse sentido, é por uma questão de coerência formal que o narrador kafkiano, embora fale pelo personagem, só mostra estar sabendo aquilo que ele realmente sabe, ou seja: nada ou quase nada. Isso explica que, na obra de Kafka, principalmente nos seus três romances, o narrador não-onisciente relate, com a maior clareza, histórias marcadas pela mais profunda ambigüidade. E é nesse passo que o leitor se descobre tão impotente quanto o herói para perceber com discernimento, e não apenas parceladamente, as coordenadas reais do mundofragmento em que ambos tateiam. No entanto é justamente essa estratégia artística que articula, no plano da construção formal, a consciência alienada do homem moderno, constrangido a percorrer às cegas os caminhos de uma sociedade de alto a baixo administrada, onde os homens estão concretamente separados não só uns dos outros, como também de si mesmos.

Seja como for, no caso de A metamorfose, não sendo o herói quem narra em nome do $e u$, mas um narrador impessoal que se refere ao herói através do pronome ele, a consequiência é que os acontecimentos não podem ser considerados alucinações do protagonista, visto que a existência deles, no plano da realidade estabelecida pelo texto, está objetivada e "aprovada": quem se responsabiliza por eles é o narrador. Além disso, a desqualificação da tese da alucinação do herói é reforçada pela atitude geral dos demais personagens, cujo olhar comprova, a todo instante, que se trata efetivamente de um inseto, e não de um homem chamado Gregor. Por outro lado, essa não-identidade de herói e narrador justifica, em larga medida, a compostura verbal da obra, pois essa linguagem desapaixonada e segura certamente seria inadequada se partisse diretamente de um eu que estivesse na situação angustiante do protagonista, que como diz Anatol Rosenfeld é a clássica situação kafkiana de barata tonta. Sendo assim, a atitude defensiva do leitor diante da novela parece derivar não só do tema que é de fato opressivo, mas também do modo de narrar. Pois uma vez que o foco narrativo está instalado na intimidade do herói, o leitor perde a garantia da distância estética como no caso do D. Quixote e se vê constantemente submetido ao perigo de se identificar com o inseto e com as suas desventuras.

Como já dissemos, essas desventuras são introduzidas com efeito de choque pela abertura, que sem dúvida alguma se pode considerar como uma das mais drásticas da história da literatura. Pois apesar de estar falando de algo empiricamente inaceitável, ela não recorre à magia tranquiilizadora do "era uma vez", característico do conto da carochinha (com o qual, aliás, Kafka aprendeu muito); pelo contrário, a fleugma e a sem-cerimônia com que este "era uma vez" é substituído por algo que simplesmente "é", vale por uma pancada na moleira do leitor.

Mas esta abertura não é, a rigor, fantástica, visto que nela não é apresentado um segundo mundo sujeito a outras leis, ou então um mundo sem leis que colidisse com o nosso, sujeito à causalidade. Gregor, como fato consumado, passa a descrever com uma precisão 
exasperante o quarto do protagonista, com as suas paredes familiares, a mesa com a coleção de amostras de tecidos e o recorte de revista emoldurado mostrando uma mulher coberta de peles. Essa justaposição direta, sem mediações - mas também sem conflitos - entre esferas normalmente incompatíveis é que torna a "catástrofe" de Gregor um acontecimento grotesco. (Vale a pena lembrar que o termo grotesco vem do italiano grotta e designa, originariamente, ornamentos da antigüidade encontrados em gruta e caracterizados pela mistura dos mundos humano, animal e vegetal. De um modo genérico, o grotesco reflete esse coquetel de esferas, que provoca em nós um efeito de estranhamento manifestado pelo arrepio ou pelo riso amarelo.)

Trata-se aqui, no entanto, de um grotesco frio, porque esse escândalo, nos quadros da contenção kafkiana, não tem nada de alarmante, o que torna a leitura, por sua vez, um verdadeiro terror. Formulado de outro jeito, prevalece aqui o que Günter Andres chamou de "explosão negativa", que consiste em não fazer soar sequer um pianíssimo onde cabe esperar um fortíssimo. Ou seja, a despeito do impacto que sofreu, o mundo conserva inalterada a intensidade do som. Se é que o humor negro - ou Galgenhumor (humor patibular) - das narrativas de Kafka tem uma explicação, então é essa.

Voltando à metamorfose, é manifesto que no mundo humano sensato, principalmente no da briosa classe média, ela não pode nem deve acontecer. Mas como aqui ela aconteceu, é compreensível que o fato seja vergonhoso para a família - uma mancha tenebrosa que precisa ser ocultada. Assim é que tanto o Sr. e a Sra. Samsa (os pais), como Grete (a irmã), se vêem na contingência de incorporar esse acidente horroroso ao seu dia-a-dia - o que aponta, pelo esquivo viés kafkiano, para a noção de que o horroroso é simultaneamente cotidiano e familiar. Na verdade porém, a despeito dos esforços da família em sentido contrário, a presença do Gregor-inseto não pode ser pura e simplesmente abolida, conservando, ao invés disso, uma gritante efetividade, que mina por dentro a vida da família. É como se o inseto, apesar de encarcerado no seu quarto, fosse sentido o tempo todo em cada canto da casa. No final, aliás, a irmã diz isso com todas as letras, quando exclama: "Esse bicho nos persegue, expulsa os inquilinos, quer ocupar a casa inteira e fazer-nos dormir na rua”. Não é preciso dizer que nesta fala se consuma, de uma maneira cristalina, uma outra metamorfose - a metamorfose da família.

Talvez fosse possível entender a metamorfose do homem em animal como uma perda de identidade. Mas justamente aqui não parece ser este o caso. Pois por mais que o herói não apareça mais para o pai, a mãe e a irmã como o antigo e estimado filho e irmão, é sintomático que se faça menção textual ao "estado atual de Gregor". Isso quer dizer que, nos termos da novela, ele continua sendo o mesmo, embora de um modo deformado e excluído da comunicação habitual. Só bem no fim da história é que a irmã exige que aquela "coisa" nojenta seja afastada do lar dos Samsa. Ela diz então ao pai, que nesse ínterim ficou muito mais brando do que o Júpiter tonitroante das bengaladas e do bombardeio de maçã nos dois primeiros capítulos: "Você precisa livrar-se da idéia de que "isso" seja Gregor. Nossa infelicidade é justamente termos até agora acreditado nisso".

A essa altura Gregor deixa de ser tratado como "ele" (er) para ser rebaixado a um simples "isso" (es). Para o narrador e o herói, porém, a identidade permanece. Isto é: a metamorfose em inseto representa de fato a perda da voz que comunica, a mudança dos gostos alimentares, dos movimentos reativos e da maneira de lidar com o espaço, ou seja: no nível da aparência, ela atesta uma redução ao estágio puramente animal de organização da vida. Mas o relato objetivo comprova que a consciência do metamorfoseado continua sendo humana e inteiramente apta a captar e compreender o que se sucede, no meio ambiente muito embora, pela mão contrária, ninguém, nesse meio, possa admitir que o inseto seja capaz disso. Dito de outra forma, Gregor está realmente transformado num bicho, mas não deixa nunca de ser Gregor. Ou seja: ele se comporta como sendo ele mesmo - e nessa medida ele é empurrado para o isolamento e a solidão (para acabar na exclusão). Isso explica que aos 
poucos a incomunicabilidade se firma como um dos temas centrais da novela. Prova disso é o fato de que a história mobiliza, nos seus três capítulos, um mesmo padrão narrativo, que é o das iniciativas inúteis de contato do herói com os membros da família e vice-versa. Os índices dessa incomunicabilidade são tantos que levaria tempo enumerá-los. Mas a título de exemplo vale a pena recordar a cena em que a mãe e a irmã decidem retirar os móveis do seu quarto, supostamente para deixar-lhe mais espaço livre, fato que no entanto o põe desesperado e disposto a saltar no rosto da irmã para salvaguardar um dos seus objetos mais queridos, que é o quadro na parede.

A novela termina, afinal, com a morte do protagonista - o que, tanto para os pais como para a irmã, significa a libertação de um trambolho que merece, inclusive, ser comemorada com um passeio ao campo. Como nós dissemos atrás, é a partir deste momento que o foco narrativo muda de lugar e insinua uma possível quebra de unidade na perspectiva escolhida por Kafka. Pois se até então o centro de orientação da narrativa estava preso à perspectiva de Gregor, como se justifica, em termos formais, que a história continue depois do seu desaparecimento de cena? Talvez tenha sido este um dos motivos que levaram o próprio Kafka a afirmar, no seu diário, que considerava o fim de $A$ metamorfose ilegível. No entanto, talvez seja viável defender o final da novela contra o desagrado do próprio autor, lembrando que ele marca, não uma quebra da unidade narrativa, mas ao contrário, um momento excepcional de encaixe da forma com o conteúdo. Pois é justamente no momento em que a família se livra da existência intolerável do inseto que o narrador também se emancipa dele, passando a contar a história de uma perspectiva que já não é mais a do próprio Gregor.

De qualquer maneira, porém, este desfecho não oferece nada de muito surpreendente para o leitor - o que certamente estava nos cálculos de Kafka. Pois a tensão e o suspense da coisa narrada não residem num desenlace que o leitor pudesse esperar com a ansiedade de quem vai resolver um quebra-cabeça. Antes, a narrativa mantém-nos presos através do jogo de contrastes tragicômicos entre as aproximações de Gregor em relação à família e as avaliações sempre equivocadas dos seus familiares. Essa travação do enredo remete, por seu turno, ao miolo da composição e ao toque estilístico inconfundível de Kafka, que é a já mencionada técnica de inversão. Isso fica claro quando se tem em mente que uma das coisas que melhor caracterizam a forma desta novela é o fato de nela estar invertida a construção épica tradicional, uma vez que ela puxa do fim para o começo o clímax da narrativa, que é a metamorfose. Isto é: aqui a coisa narrada não caminha para o auge, ela se inicia com ele - e com isso a novela se sustenta mais sobre as decorrências de um fato fundamental do que numa progressão rumo a ele (de uma maneira semelhante, aliás, ao que acontece no Édipo rei de Sófocles).

No entanto expressões literais como "o estado atual de Gregor" sugerem que a metamorfose do herói pode ser entendida como o resultado de um processo, ou seja: como um momento definido que teria sido precedido por outros que ficaram aquém da narrativa e que por isso não foram tematizados por ela. Tanto isso é verdade que o herói, no percurso da obra, reconstrói (à maneira de Édipo...) lances anteriores da sua vida, onde repontam não só as queixas contra a profissão desumana de caixeiro-viajante, também projetos generosos (por exemplo, financiar o estudo de música da irmã) e detalhes importantes sobre a sua posição familiar. Desse modo ficamos sabendo, por meio de indiscrições feitas em tom inocente, que até então Gregor tinha sido arrimo de família, sustentando os seus membros com o sacrifício pessoal do seu trabalho e saldando as dívidas deixadas há cinco anos pelo pai falido. Por sinal que este havia guardado um bom pecúlio, sem que Gregor tivesse notícia disso (ele só toma conhecimento do fato quando ouve, encerrado no seu quarto, mas com a porta entreaberta, os serões familiares) - o que sem dúvida insinua uma rasteira do pai em relação ao filho, pois a conclusão mais óbvia é que Gregor estava se esfalfando mais que o necessário na firma onde era viajante e cujo diretor é o credor do pai. Esses pormenores soltos, uma vez amarrados coisa que o herói não faz, mas que Édipo fez - eletrizam, por assim dizer, o conjunto da 
história, a ponto de encaminharem uma explicação para o seu nó górdio, que é a metamorfose. Pois as consequiências imediatas desta são: 1) retirar da família a base econômica do seu sustento (evidentemente fundado na exploração do trabalho do filho) e 2) libertar Gregor da sua condição de escravo assumido. Vistas as coisas por este ângulo é admissível supor que o inseto Gregor é inútil porque já não produz, só consome; ao mesmo tempo em que Gregor, o inseto, é a forma sensível de uma libertação. Se essa conjectura for pertinente, o que então se percebe é mais uma vez a vigência do princípio de inversão em que Kafka é um mestre insuperável; pois se antes a família vivia parasitariamente às custas do trabalho de Gregor e da sua alienação no mundo dos negócios (que contrasta, na novela, com a utopia do "mundo da música") ele agora é, aos olhos da família "deserdada" pela metamorfose, apenas um inseto parasita.

A esta altura é necessário fazer um parêntese e recordar que Kafka construiu várias das suas histórias tomando ao pé da letra metáforas fossilizadas da linguagem corrente como, por exemplo, "sofrer na própria pele", da qual ele partiu para escrever a novela "Na Colônia Penal", onde o estilete de uma máquina diabólica grava nas costas do réu a sentença a que ele foi condenado.

No caso de A metamorfose é possível pensar que a metáfora subjacente tenha sido uma expressão como Luftmensch (literalmente: "homem aéreo"), como a qual Marx, por exemplo, designa o cidadão sem ocupação definida ou desligado do processo material da produção, e que por isso mesmo "esvoaça" no contexto social.

$\mathrm{Na}$ realidade porém parece ser mais interessante recorrer ao modo peculiar de construção da obra - que como vimos coloca o clímax no começo - e nesse passo examinar melhor a frase de abertura. Todos a conhecem, mas não custa repeti-la: "Quando Gregor Samsa acordou, certa manhã, de sonhos intranqüilos, encontrou-se metamorfoseado em sua cama num inseto monstruoso". Esta tradução é horizontal e "correta", mas perde alguns dos ingredientes básicos do original - como, por exemplo, a reiteração de três negações pelo prefixo alemão un- (unruhig, ungeheuer, Ungeziefer), as quais, de certo modo, prefiguram o clima ruim da novela, que, como disse Roberto Schwarz, é uma história que começa mal e termina pior ainda. Mas a tradução não perde só com isso como também certas ressonâncias relevantes de sentido, contidas na expressão ungeheures Ungeziefer (inseto monstruoso). É pouco provável que ela tenha sido colocada neste lugar crucial da obra por acaso, uma vez que Kafka, além de calibrar cada vocábulo na redação de uma sentença, era etimologista amador e, nessa qualidade, conhecia os segredos conceituais escondidos no bojo das palavras.

Para o que agora nos interessa, o adjetivo ungeheuer (que significa monstruoso e, como substantivo - das Ungeheuer - significa "monstro"), quer dizer, etimologicamente, "aquilo que não é mais familiar, aquilo que está fora da família, infamiliaris" e se opõe a geheuer, isto é, aquilo que é manso, amistoso, conhecido, familiar. Por sua vez, o substantivo Ungeziefer (inseto), ao qual ungeheuer se liga, tem o sentido original pagão de "animal inadequado ou que não se presta ao sacrifício", mas o conceito foi se estreitando e passou a designar animais nocivos, principalmente insetos, em oposição a animais domésticos como cabras, carneiros etc. (Geziefer).

Esses dados são significativos na medida em que o seu conjunto oferece a mediação da própria matriz verbal do texto para sustentar a sugestão referida atrás de que a metamorfose de Gregor representa uma conversão do parasitado da família ao suposto parasita dela, ou seja: a passagem daquele que se sacrifica para aquele que já não pode ser sacrificado, do adequado para o inadequado, do idêntico para o diferente, do reconhecido para o que perdeu o reconhecimento, do familiar para o não-familiar, do "ele" para o "isso", do manso para o monstro, do Gregor-homem para o Gregor-inseto.

Reconhecido este roteiro, que recupera o nível arqueológico da linguagem - o que não desmente, antes confirma, os desígnios artísticos de Kafka - fica certamente mais fácil achar que $A$ metamorfose deve ser lida em primeira linha (e a partir da primeira linha) não como 
uma simples novela fantástica, mas como uma trágica história de família. Pois esquivando-se à inconseqüência da mera diversão ela condensa, em algumas imagens inesquecíveis, que já fazem parte da literatura universal, o que mais tarde Adorno (1977) exprimiu numa frase lapidar: "A origem social do indivíduo (a família) revela-se no final como a força que o aniquila". 